\title{
The evaluation of the fibromyalgia patients
}

\author{
La valutazione del paziente fibromialgico
}

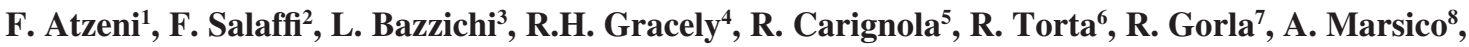 \\ F. Ceccherelli', M. Cazzola ${ }^{10}$, D. Buskila ${ }^{11}$, M. Spath ${ }^{12}$, M. Di Franco ${ }^{13}$, G. Biasi ${ }^{14}$, G. Cassisi ${ }^{15}$, \\ S. Stisi ${ }^{16}$, R. Casale $^{17}$, L. Altomonte ${ }^{18}$, G. Arioli ${ }^{19}$, A. Alciati ${ }^{20}$, G. Leardini ${ }^{21}$, F. Marinangeli ${ }^{22}$, \\ M.A. Giamberardino ${ }^{23}$, P. Sarzi-Puttini ${ }^{1}$ (Italian Fibromyalgia Network)
}

\begin{abstract}
${ }^{\prime}$ Rheumatology Unit, L. Sacco University Hospital, Milan, Italy; ${ }^{2}$ Department of Rheumatology, Polytechnic University of the Marche Region, Ancona, Italy; ${ }^{3}$ Department of Internal Medicine, Division of Rheumatology, S. Chiara Hospital, University of Pisa, Italy; ${ }^{4}$ Department of Medicine, University of Michigan Health System, Ann Arbor, Michigan, USA; ${ }^{5}$ Department of Neuroscience, University of Turin, A.S.O. San Giovanni Battista of Turin, Turin, Italy; ${ }^{6}$ Department of Neuroscience, University of Turin, A.S.O. San Giovanni Battista of Turin, Turin, Italy; ${ }^{7}$ Rheumatology and Clinical Immunology, Spedali Civili and University of Brescia, Italy; ${ }^{8}$ Rheumatology Unit, Hospital of Taranto, Taranto, Italy; ${ }^{9}$ IOV (Veneto Cancer Institute), IRCCS, Department of Pharmacology and Anesthesiology,

University of Padua, Italy; ${ }^{10}$ Unit of Rehabilitative Medicine "Hospital of Circolo", Saronno (VA), Italy; ${ }^{11}$ Department of Medicine H, Soroka Medical Center and Faculty of Health Sciences, Ben Gurion University, Beer Sheva, Israel; ${ }^{12}$ Friedrich-Baur-Institute,

University of Munich, Munich, Germany; ${ }^{13}$ Chair of Rheumatology, University la Sapienza Rome, Rome, Italy; ${ }^{14}$ Unit of Rheumatology, University of Siena, Siena, Italy; ${ }^{15}$ Rheumatology Branch, Specialist Outpatients' Department, Belluno, Italy; ${ }^{16}$ Rheumatology Unit,

"G.Rummo" Hospital, Benevento, Italy; ${ }^{17}$ Department of Clinical Neurophysiology and Pain Rehabilitation Unit, Foundation Salvatore Maugeri, IRCCS, Scientific Institute of Montescano, Montescano (PV), Italy; ${ }^{18}$ UOC of Rheumatology Hospital S. Eugenio, Rome, Italy; ${ }^{19}$ Division of Rehabilitative Medicine and Rheumatology, General Hospital of Pieve di Coriano (Mantua), Italy;

${ }^{20}$ Department of Psychiatry, L. Sacco University Hospital, Milan, Italy; ${ }^{21}$ Rheumatology Unit, SS Giovanni e Paolo Hospital, Venice, Venice, Italy; ${ }^{22}$ Department of Anesthesiology and Pain Medicine, L'Aquila University, L'Aquila, Italy;

${ }^{23}$ Ce.S.I. "G. D'Annunzio” Foundation, Department of Medicine and Science of Aging, “G. D'Annunzio”, University of Chieti, Italy
\end{abstract}

$\overline{\text { Competing interests: none declared }}$

\section{RIASSUNTO}

La sindrome fibromialgica $(F M)$ è una condizione di frequente riscontro nella pratica clinica caratterizzata da dolore muscoloscheletrico cronico e diffuso, sensazione di tensione elo di rigidità muscolare e articolare, affatticabilità, disturbi del sonno, alterazioni del tono dell'umore e dolore alla digitopressione di almeno 11/18 tender points (TPs). Fino ad oggi, non disponiamo né di esami strumentali né di marcatori specifici per effettuare la diagnosi di FM; infatti, la maggior parte degli esami attualmente disponibili sono utili solo ai fini di ricerca. La maggior parte delle diagnosi differenziali può essere effettuata mediante un accurato esame clinico e anamnestico. Se consideriamo il possibile overlap tra la FM ed altre malattie, il medico curante dovrebbe sottoporre tutti i pazienti con sospetta FM a radiografia del torace ed ecografia dell'addome, oltre ad un accurato esame obiettivo. La risonanza magnetica funzionale ha messo in evidenza diverse alterazioni sovraspinali nei pazienti affetti da FM, una condizione clinica a patogenesi sconosciuta. Nei pazienti affetti da FM sono diversi i trattamenti utilizzati, ma valutarne il loro effetto è difficile poiché questa sindrome presenta molteplici aspetti. Al fine di identificare un "core outcome domains", l'iniziativa dell' IMMPACT e il workshop OMERACT ha convocato un meeting per sviluppare le raccomandazioni utili per $i$ trials clinici sul dolore cronico.

Reumatismo, 2008; 60: Supplemento 1: 36-49

\section{INTRODUCTION}

F ibromyalgia (FM) is a rheumatic disease characterized by musculoskeletal pain, chronic diffuse tension and/or stiffness from joints and mus-

Corresponding author:

Fabiola Atzeni, MD, PhD

Rheumatology Unit

L. Sacco Hospital, Milan, Italy

E-mail atzenifabiola@hotmail.com cles, easy fatigue, sleep and emotional disturbances, and pressure pain sensitivity in at least 11 of 18 tender points (TP) $(1,2)$. This disease has an incidence of $2 \%$ in the general population, but it is found more often in middle-aged women $(3.4 \%)(3,4)$. The etiopathogenesis of FM has not been clarified yet. FM patients have a dysregulation of pain neurotransmitters and neurohormone-mediated association with irregularities in the physiology of sleep. The American College of Rheumatology (ACR) 
criteria diagnostic criteria for FM are based upon chronic widespread pain and tenderness in 11 of 18 defined muscular sites (1). Recent evidence suggests that the tenderness component of FM is not confined to these sites; rather, it is present throughout the body, including non-muscular sites such as the thumb. The widespread nature of spontaneous pain in FM implicates general mechanisms that may involve spinal or supraspinal modulation of normal peripheral input, or effector mechanisms that alter pain sensitivity at the periphery. These mechanisms are likely observed at supraspinal sites. Functional neuroimaging of the brain has opened a window into the supraspinal processes in health and disease (5). With a few exceptions, these methods infer neural activity in the brain by changes in regional cerebral blood flow (rCBF). This inference is based on the principle that localized brain activity signals a discreet increase in $\mathrm{rCBF}$ to meet the metabolic demands of this increase in neural activity. The increase in $\mathrm{rCBF}$ occurs after a hemodynamic delay of a few seconds and is closely coupled to the magnitude and duration of the activity. Most functional imaging methods are based on the evaluation of the time course of changes in $\mathrm{rCBF}$ throughout the brain (6).

The absence of anatomopathological lesions and biohumoral abnormalities, demonstrated with classical instrumental methods, has led to considerable difficulties in diagnosis. The diagnostic criteria frequently overlap with those of other diseases; in fact, some patients with chronic fatigue syndrome (CFS) meet the criteria for FM, and an FM-like framework may be present even in non-rheumatic diseases.

For example, patients with hypothyroidism show musculoskeletal pain that is similar FM. The diagnosis based on the ACR criteria, therefore, must be accompanied by the exclusion of diseases that have symptoms, but not causes, in common with FM as evidenced by the evaluation of markers and humoral scans (miositis, rheumatic polmyalgia, spondyloarthritis, etc.) (7). Often, FM is comorbid with other diseases that act as confounding and aggravating factors (Sjögren, systemic lupus eriythematosus (SLE), rheumtoid arthritis (RA), thyroid disease). There are no instrumental tests to confirm the diagnosis of FM; and many differential diagnoses may be excluded by an extensive clinical examination and patient history. Considering the overlap of FM with other medical conditions, treating physicians should be vigilant: chest- $\mathrm{X}$-rays and abdominal ultrasonography are the first steps to- ward general evaluation of all patients with suspected FM. An individualized, multidisciplinary range of treatments should be employed to treat the various symptoms that patients experience. Although some of these therapies have been tested in randomized controlled trials (RCT), there has been little standardization in the approach to these trials and in the outcome measures used. Evaluating therapeutic effects in FM patients is difficult because of the many facets of the syndrome. To address the identification of core outcome domains, the Initiative on Methods, Measurement, and Pain Assessment in Clinical Trials (IMMPACT) (8) and Outcome Measures in Rheumatoid Arthritis Clinical Trials (OMERACT) (9) workshop convened a meeting to develop consensus recommendations for chronic pain clinical trials.

\section{LABORATORY AND INSTRUMENTAL EVALUATIONS IN PATIENTS WITH FM}

In clinical studies and observational research studies, FM is usually diagnosed by application of the ACR criteria (1). Moreover, diagnosis is made by a combination of patient history, physical examination, laboratory evaluations and exclusion of other causes for symptoms attributed to FM $(10,11)$.

\section{BIOMARKERS IN FM}

\section{Serum}

Compared to healthy subjects or patients with other diseases, FM patients present with high antipolymer antibodies (APA) (12) and antiserotonin antibody (13) values, with contrasting results in the Italian population. The APA positivity in a recent work appears to be less than that evidenced in the USA, and it appears to correlate with the severity of the disease; this result could be due to a different ethnic origin of the populations studied. Other antibodies (antiganglioside and antiphospholipids) were identified in FM patients compared to healthy subjects, but the sensitivity and specificity was not clear. Patients with FM have a higher frequency of anti-thyroid antibodies, and their values seem to be correlated with the presence of certain symptoms (14). Recent studies have shown higher hyaluronic acid values in FM patients compared to healthy controls, but this data has not been confirmed $(15,16)$. Alterations of branched-chain amino acids (valine, leucine, isoleucine), pheny- 
lalanine (17), and collagen cross links, and particularly, a reduction in the ratio of pyridinoline to deoxypyridinoline as well as decreased levels of hydroxipyroline (18) were also found. Neopterin has been suggested as an inflammation marker, which has an inversely proportional relationship with Ltryptophan availability. Other studies showed low serum levels of 5-HT in FM patients compared to both healthy controls and patients with rheumatic diseases such as RA. These studies provide indirect evidence supporting the alteration of 5-HT metabolism in FM subjects. In a recent study, FM patients exhibited a tendency to have lower serotonin levels than patients with RA and healthy controls; but the variation of serotonin levels within the disease groups is too broad to differentiate FM from other conditions, especially depression (19). There is also evidence to suggest that FM patients may have alterations in the expression of 5-HT transporters due to a transcriptional polymorphism in the region that could lead to an increase of the same transcriptional region (20). Another study has suggested that an alteration of the growth hormone $(\mathrm{GH})$, an indirect modulator of the immune system that interacts with the hormonal system, seems to protect the body from the immunosuppressive effects of glucocorticoids during stress (21) and favours IGF1-mediated muscle repair. Altered serum cortisol and melatonin levels were found; these hormone secretions are closely associated with the circadian rhythms. The study also found alterations of 5-HT, somatomedin C, calcitonin gene-related peptide, calcitonin and cholecystokinin which are possible indicators of FM widespread pain (22). Studies conducted on FM patients showed an increase in plasma levels of IL-6 and IL8 compared to healthy controls, an increased production of IL-1 and TNF-alpha, and a reduced production of IL-2 and IFN-alpha, which highlights an immune activation and a down-regulation of the HPA. A study showed an increase in plasma IL-10, IL-8 and TNF-alpha in FM patients independent of the presence of psychiatric comorbidity; this supports the hypothesis of an activation of the immune system (23). Abnormal levels of ACTH, 5-HT, IGF-1 and FT4 were found, which suggests an alteration of the endocrine system in this disease (14). The role of free radicals in FM is controversial, as this could suggest that FM is also an oxidative disorder; studies have shown high levels of malondialdehyde, markers of oxidative damage, and low levels of superoxide dismutase, an intracellular antioxidant (24) in FM.

\section{Urine}

The stress factor is probably crucial in this condition and alterations of the urinary corticotropin-releasing factor (CRF)-L1, catecholamine, cortisol, with the haplotypes of catecholamine COMT gene (25) were recently found; as in the serum, crosslinks of collagen, a reduction in the ratio of pyridinoline to deoxypyridinoline and decreased levels of hydroxyproline (18) were found in the urine.

\section{Cerebrospinal fluid}

In FM subjects, substance P levels increase in cerebrospinal fluid and this event leads to the release of IL-6. Substance P induces the production of IL8 , a pro-inflammatory cytokine, which stimulates the passage of neutrophils through the vascular walls. Altered levels of serotonin and increased corticotropin-releasing hormone (CRH) and a pool of proteins (alpha-1-macroglobulina, keratin 16, orosomucoide, amyloid precursors etc.) were also found in the cerebrospinal fluid of FM patients (26). Among FM patients, pain, but not fatigue, was associated with the concentration of CRF in the cerebrospinal fluid (27).

These data support the hypothesis that abnormalities in the stress response are associated with FM pain. In FM subjects, a reduction of glial cellderived neurotophic factor was also found (28); this result could be related to the role of this neurotophic factor in preventing and reversing abnormalities that develop in chronic pain conditions.

Somatostatin levels appear to be reduced in the cerebrospinal fluid of FM patients and significantly correlated with reduced levels of neurotophic factor.

\section{Isolated cells}

Alterations of the immune cells have been studied in FM patients, highlighting an abnormal lymphocyte and cytokine (IL-6-8-10 TNF-alpha) response related to FM. Specifically, the number of T lymphocytes and the immunoglobulin $\mathrm{M}$ level appear to be altered, and the number of natural killer cells appears to be reduced. In FM patients, reduced activation of T lymphocytes was also found. The cell receptors, especially the peripheral benzodiazepine receptor (PBR), the 5-HT receptors and the 5-HT re-uptake system were altered. Studies conducted on platelets have shown a reduced receptor density and functionality of 5-HT and its carrier, which were identified by lower 5-HT re-uptake rate from the synaptic cleft (29). Other research has shown 
an up-regulation of PBR, also related to the severity of illness (30). In the platelets of FM patients increased intracellular concentrations of calcium and magnesium ions and decreased ATP levels were also found. In a recent study (31), a comparison was made between FM patients, subjects with complex regional pain syndrome (CRPS) and healthy controls regarding the influence of pain on subpopulations, lymphocyte number, and the ratio of Th1 to Th2 cytokine in T lymphocytes. The lymphocyte number did not differ between groups, but there was a significant reduction of cytotoxic CD8+ lymphocytes in FM and CRPS patients.

\section{Tissues}

In skin biopsies an increase of activated mast cells has been observed (25). It appears that muscle tissue does not exhibit alterations at the cellular level; and while the data appear inconsistent, inflammatory infiltrates have not been found. The skin of FM patients shows unusual patterns of unmyelinated nerve fibers as well as Schwann cells; if these results are replicated in a larger study, these abnormalities may contribute to the lower pain threshold of FM subjects (32).

\section{INSTRUMENTAL STUDIES}

Studies that employ existing or innovative testing devices or methodologies are usually negative, and these testing methodologies are not recommended for purposes of screening or diagnosis (33); however, imaging tests can be used to exclude concomitant illnesses that could resemble FM.

The following overview of comorbidities highlights the need for improved instruments for accurate assessment of FM. Environmental factors can influence both the development of FM and a number of "stressors" that are temporally correlated with the onset of the syndrome, including trauma, infections (e.g., hepatitis $\mathrm{C}$ virus, HIV, and Lyme disease), emotional stress, catastrophic events (e.g., war), autoimmune diseases and other pain conditions $(34,35)$. FM has been reported to coexist in $25 \%$ of patients with RA, $30 \%$ of patients with SLE and 50\% of patients with Sjogren's syndrome (36-38).

The most common rheumatic diseases that could overlap and be confused with FM are: osteoarthritis (OA), RA, ankylosing spondylitis (AS), polymyalgia rheumatica (PMR), SLE, Sjogren's syndrome, osteomalacia, polymyositis.
OA is observed most often in people over age 50 (most of them are asymptomatic); OA, together with FM, is among the most prevalent (7\%) rheumatic syndromes in clinical practice (39). OA can be confused with FM because it causes arthralgias of the whole body and could be associated with significant limitation of activity. It has a clear predilection for certain joints, in particular, the first carpometacarpal joints, cervical and lumbar spine, hips, knees and metatarsophalangeal joints (40). Radiographically, OA has classic changes that include osteophyte formation, joint space narrowing, subchondral sclerosis, and subchondral cysts (41). It may seem reasonable to study the painful region on radiograph, but radiographs are not necessarily correlated with clinical symptoms and must be interpreted correctly in the clinical context.

RA is an inflammatory arthritis; the patients present with inflammatory symptoms. The historical evaluation and the physical examination are fundamental to determine, for example, if real synovitis is present. The radiographic manifestations of RA have been well described (marginal erosions, joint space narrowing, joint destruction), and disease-specific alterations that can be seen during the clinic visit (e.g., soft tissue swelling, deformities, subluxations) could be partially found on radiographs. In fact, it takes months or years to develop these alterations, which emphasizes the importance of developing new instrumental assessments that will facilitate early diagnosis of RA. Magnetic resonance imaging (MRI) is the gold standard for confirming the diagnosis of RA, but is too expensive for normal management. Muscoloskeletal ultrasonography is easy to perform, can be repeated without X-ray exposure risks for patient, and represents the best compromise between cost and result (42-44). The ultrasonography evaluation of the patient could help the clinician to identify the elements for RA or FM diagnosis.

AS usually begins with an insidious onset of chronic inflammatory back pain symptoms in adolescence or early adulthood (45). AS can be easily mistaken for FM, because both diseases occur in young patients who may have constitutional symptoms such as malaise, fatigue and impaired sleep (45). The hallmark of AS is sacroiliitis as identified radiographically via conventional pelvic Xray, although this condition may not be evident in the early stages of the illness (46). Sacroiliitis does not occur in FM, though, so its presence is fundamental in distinguishing AS from FM. Recent reports indicate that the role of MRI has become 
clearer and it may be a better tool for early identification of these patients (47).

PMR is characterized by widespread pain and profound morning stiffness. Patient's historical factors (age, distribution of pain and stiffness) and laboratory tests can help to distinguish FM from PMR. The response to prednisone therapy is dramatic in PMR (24 to 48 hours), whereas no response is present in FM. Instrumental tests are not helpful to diagnose both diseases.

FM could mimic SLE as demographic and clinical features overlap: young women, fatigue, dermatological involvement, arthralgias $(48,49)$. However, organ system involvement such as malar rash and photosensitivity, fever, serositis, haematological alterations, and neurological signs typically occur in SLE whereas these elements are not present in FM (50). Conventional X-rays, ultrasonography, computed tomography, MRI help clinicians to diagnose SLE and to distinguish SLE from FM.

Fatigue and generalized arthralgias are common for Sjogren's syndrome and FM. The fundamental clinical features of Sjogren's syndrome are dry eyes and dry mouth. In FM mucosal dryness is related to sympathetic hyperactivity (51). Sjogren's syndrome is also characterized by damage to the eye epithelium whereas no damage is evident in patients with FM. Rose bengal and/or fluorescein dyes are used by oculists to identify this hallmark feature. In recent years, salivary gland ultrasonography became a simple and noninvasive test for the detection of gland involvement in Sjogren's syndrome; color doppler sonography can also increase diagnostic accuracy (52). Both methods are important to differentiate Sjogren's syndrome from FM.

The radiographic evidence of osteopenia with pseudofractures distinguishes osteomalacia from FM (24). Bone density in FM patients is comparable to healthy controls (53).

Profound proximal muscle weakness with mild pain is typical of polymyositis. The muscle biopsy is the gold standard in the diagnosis of this inflammatory myopathy. The histological features of polymyositis include variability in muscle fiber size, scattered necrotic and regenerating fibers and endomysial inflammation with invasion of nonnecrotic muscle fibers (54). Use of electromyography increases spontaneous and insertional activity with fibrillation potential, complex repetitive discharges, positive sharp waves, small polyphasic motor unit potentials and early recruitment (54). Muscle biopsy and electromyography are normal in FM patients.
Nonrheumatic syndromes that could overlap and be confused with FM include thyroid dysfunction and hepatitis $\mathrm{B}$ and $\mathrm{C}$ virus infection.

Thyroid dysfunction. Hypo- and hyperthyroidism are characterized by profound fatigue and muscle weakness. Anxiety may be presented in hyperthyroidism.

There are significant similarities between the clinical findings in FM and the symptoms of thyroid dysfunction (55). Many studies report that a considerable proportion of FM patients has problems in the production or utilization of thyroid hormones (56); therefore, signs of thyroid dysfunction must be investigated in FM patients. When clinically indicated, thyroid function tests may be performed. Gland ultrasonography can be helpful, but the instrumental results are not necessarily indicative of disease as thyroid tissue abnormalities can be present in healthy subjects, too.

Hepatitis B and C virus (HBV/HCV) infection. Patients with $\mathrm{HCV}$ infection may frequently present some rheumatologic manifestations such as FM (57). Diffuse musculoskeletal pain is present in approximately half of $\mathrm{HB}$ antibody positive patients and approximately $25 \%$ of $\mathrm{HB}$ antigen positive patients present with FM syndrome (58). Hepatic ultrasonography indicates liver alterations and is an important test for differentiating FM from hepatitis B or C infections.

Generalized pain is a feature of many malignant diseases, including multiple myeloma, and metastatic breast, lung and prostatic cancer (59). Usually FM does not predict cancer, but an increased risk of breast cancer was found among those female patients that did not satisfy the ACR criteria for FM (60). Clinicians must be vigilant of those patients that develop any symptoms of breast malignancy and thoroughly screen using procedures such as mammography.

\section{Tilt test}

The tilt table test is another useful tool to study orthostatic intolerance and syncope. The method is based on the physiological changes that occur after adopting an upright posture with pooling of approximately $700 \mathrm{ml}$ blood in the lower parts of the body. In normal circumstances, the autonomic nervous system quickly compensates for this relative volume loss by increasing vascular tone and cardiac output. This mechanism serves to prevent hypotension and inadequate cerebral perfusion. Tilt table testing examines this response in a controlled environment. 
With passive orthostasis, additional stress is exerted on the sympathetic nervous system by blocking the influence of muscle contraction that could increase venous return. Subjects are supine for 30 minutes in the first step. The subject is then tilted upright for 30-45 minutes at an angle of $60-80^{\circ}$. Pharmacological stimulation with isoproterenol is sometimes used as an additional step. The normal responses to tilting consist of an increase in heart rate of 10-15 beats per minute, an elevation of diastolic blood pressure of about $10 \mathrm{mmHg}$, and little change in systolic pressure. There are two types of abnormal responses. One response is orthostatic hypotension, defined as a reduction of systolic blood pressure of at least $20 \mathrm{mmHg}$ or a reduction of diastolic blood pressure of at least $10 \mathrm{mmHg}$. This hypotension may induce syncope (61). The other type of abnormal response is postural orthostatic tachycardia, which consists of a sustained increase in heart rate of at least 30 beats per minute or a sustained pulse rate of 120 beats per minute. Tilt table testing has been used mostly to study syncope in patients with no evidence of structural heart disease. Furlan et al. (62) showed that, while recumbent, patients with FM seemed to experience a global increase of central cardiovascular sympathetic activity and a blunted enhancement of sympathetic activity. A blunted enhancement of sympathetic modulation to the vessels and impaired cardiac vagal withdrawal characterized their autonomic profiles during gravitational stress and may have accounted for the excessive rate of syncope they experienced upon standing.

\section{Polysomnography}

Patients with FM often complain of poor sleep quality. Polysomnography (PSG) is a recording of sleep stages and architecture that is used to investigate underlying pathology, including sleep apnea. Sarzi-Puttini et al. (63) reported that FM patients complaining of daytime hypersomnolence had a higher number of TPs, a greater score of subjective pain and more fatigue than FM patients with no daytime hypersomnolence. Moreover, hypersomnolent patients slept significantly less efficiently, had a lower proportion of stages 3 and 4 sleep, and had twice as many arousals per hour of sleep compared to patients with no hypersomnolence. Rizzi et al. (64) reported that FM patients experience an increased cyclic alternating pattern (CAP) rate, which indicates poorer quality of sleep. Further, these data are strongly correlated with severity of symptoms.

\section{FUNCTIONAL NEUROIMAGING}

The first studies that used functional neuroimaging to evaluate brain processing in fibromyalgia patients used the method of single photon emission computed tomography (SPECT). SPECT quantifies regional cerebral blood flow (rCBF) by detecting the distribution of a radioactive tracer that is infused before the scan. Mountz et al. (65) evaluated baseline levels of $\mathrm{rCBF}$ in ten patients with FM and in seven healthy control subjects. After the tracer infusion the participants sat quietly for the duration of the 32-minute SPECT scan. This method produced images with a resolution of about $8.5 \mathrm{~mm}$ in predefined regions of interest (ROI) corresponding to the right and left thalamus and right and left head of the caudate nucleus. Patients, relative to controls, had lower rCBF in both the right and left thalamus and in both the right and left caudate nucleus. Kwiatek et al. (66) subsequently performed a similar study using SPECT in 17 patients with FM and in 22 healthy control subjects and found decreased $\mathrm{rCBF}$ in the right thalamus but no decreases in either the left thalamus or in the caudate nuclei of FM patients. Additional activations were found in the inferior pontine tegementum and near the right lentiform nucleus of patients. The consistent finding of reduced baseline $\mathrm{rCBF}$ in the right thalamus was replicated by Cohen-Gadol et al. (67) and has been observed in patients with pain associated with traumatic peripheral neuropathy (68) and metastatic breast cancer (69).

During the time of these initial SPECT studies in FM, functional magnetic resonance imaging (fMRI) methods were being developed to assess brain activity with greater temporal and spatial resolution than either SPECT or positron emission tomography (PET). The commonly used fMRI method of blood oxygen level dependent (BOLD) imaging has the further advantage of not requiring the infusion of a radioactive tracer. The first study to apply fMRI to the evaluation of FM evaluated brain responses to painful blunt pressure applied to the thumb (6). This study assessed the pressure pain sensitivity in patients and control subjects before and during the fMRI experiments. For each of 16 FM and 16 control participants, this study determined pressures that evoked pain described as near "slightly intense" on a calibrated pain scale $(6,70)$. The comparison of the effects of these subjectively equal evoked pain sensations (produced by approximately half the pressure in the fibromyalgia patients) defined the equal pain contrast. The 
healthy control subjects received an additional scan in which they received the same low pressures that were delivered to the patients (equal pressure contrast). These pressures provoke ratings of "slightly intense" pain by the FM patients, and ratings of "not painful" or "faintly painful" by the control subjects. Pressures were applied to the thumbnail by a $1-\mathrm{cm}$ diameter hard rubber probe attached to a hydraulic cylinder. The thumb site was chosen for its dense innervation and its large representation in the primary somatosensory cortex. The thumb was also chosen to test the concept that tenderness in FM is not due to muscle sensitivity or confined to muscles at specific tender point sites, but rather, it is a property of deep tissue and is found throughout the body in these patients.

The patients underwent an fMRI scan during which 30 seconds of painful pressure (e.g., $2 \mathrm{~kg}$ ) was alternated with 30 seconds of non-painful pressure (e.g., $0.5 \mathrm{~kg}$ ) for the duration of the 10 -minute scan. Control participants underwent the same type of scan whereby painful pressure alternated with nonpainful pressure (equal pain control), and an additional scan in which the painful pressure was reduced to the values delivered to the patients (equal pressure control). All participants also received a conventional anatomical MRI of the head to facilitate localization of the fMRI-derived brain activity. During the anatomical session complete functional images of the entire brain and cerebellum were obtained every 5 seconds, with a resolution of $3 \mathrm{~mm}$ in all three dimensions. These data were processed by standard methods (6), and the result is a statistical volume, or map, of each subject's brain that represents the statistical results of the difference between painful and nonpainful pressure. To perform group analyses, each of these volumes was converted to standard coordinates and presented as group activity for each group or as a statistical difference between groups. The results show that a similar experience of pain (the equal pain contrast), which was produced using about half the amount of pressure in patients compared to controls, was associated with similar activations in a number of brain regions that are usually activated in pain imaging experiments. These include contralateral primary (SI) and secondary (SII) somatosensory cortex, insular cortex and inferior parietal lobule. In this case the brain response appears to be consistent with the verbal reports of the subjects. A second analysis evaluated the effects of the equal pressure contrast by identifying regions in which the same pressure produced greater effects in one of the groups. The relatively low pressure of $2 \mathrm{~kg}$ evoked significantly greater activity in a number of brain regions in FM patients, including both regions found in the first analysis and additional regions such as anterior cingulate cortex.

This result with painful pressure has been found with painful heat as well. Cook et al. (5) administered similarly painful, 10 -second heat stimuli to the left hand of nine female FM patients and nine female healthy controls. The reduced heat tolerated by patients (mean $47.4^{\circ} \mathrm{C}$ ) compared to controls $\left(48.3{ }^{\circ} \mathrm{C}\right)$ resulted in no significant differences in brain activation. This study also showed evidence of increased activity in the contralateral insular cortex of patients.

Additional studies have characterized regions that show graded responses to stimulus intensity and regions that appear to show a binary response to painful stimulation, i.e., turning on at some threshold level of stimulation (71). Both patients and controls have shown graded responses to stimulus pressure in regions that are involved in processing the sensory-discriminative dimension of pain sensation, including contralateral (right) thalamus, and primary (SI) and secondary (SII) somatosensory cortex.

These initial studies explored the effects of the amount of painful stimulation on the pattern and magnitude of brain responses. A large body of evidence indicates that pain perception and behavior are much more complex and influenced by a number of variables such as mood and cognition. An additional group of studies have begun to investigate this complexity by using fMRI to evaluate the modulation of evoked pain by mood or cognitive variables that have been shown to influence pain and pain behavior.

Depression is a significant factor in the expression of pain and response to treatment. Giesecke, et al. (72) evaluated the effects of depression on brain response to pressure pain in FM. Thirty FM patients and 7 control participants received fMRI scans during alternating pressure and no pressure stimulation using methods similar to the initial fMRI study described above by Gracely, et al. (6). However, instead of comparing two groups, the first analysis compared three groups: 7 age- and gender-matched control subjects, 7 FM patients diagnosed with major depressive disorder, and 7 matched fibromyalgia patients without major depressive disorder. Equally painful stimuli, produced by significantly lower stimulus pressures in the FM patients, resulted in similar activations in all three groups. 
These activations were in regions implicated in processing the sensory-discriminative dimension of pain, including contralateral SI and SII. The patients with major depressive disorder showed additional activations in bilateral amygdala and in a specific region of the contralateral anterior insula. A second analysis examined the influence of depression using a correlational method in all $30 \mathrm{FM}$ patients in which the level of pain-induced brain activation for each subject was correlated with the symptoms of depression, as measured by the Center for Epidemiological Studies Depression Scale (CES-D). No associations between depression and pressure pain sensitivity were found in brain regions associated with processing the sensory discriminative dimensions of pain. CES-D scores, however, were significantly associated with painevoked activity in brain regions implicated in processing the motivational-affective dimensions of the pain experience, specifically the contralateral anterior insula and bilateral amygdale, the same regions identified in the between groups analysis. These results suggest that depression modulates pain-evoked activity in structures involved in processing affective characteristics of pain experience. Similar correlation analyses have been applied to the cognitive variable of catastrophizing, which is emerging as a significant variable predicting pain chronicity and poor treatment response (73). Since this cognitive style has been linked to depression, the analysis controlled for depression statistically. The results correlating catastrophizing with painevoked activity in each subject found significant associations in brain regions related to the anticipation of (contralateral medial frontal cortex, ipsilateral cerebellum) and attention to (contralateral anterior cingulate gyrus, bilateral dorsolateral prefrontal cortex) pain, and to both emotional (ipsilateral claustrum, interconnected to the amygdala) and motor (contralateral lentiform nuclei) responses (74). These results suggest that the effects of negative cognitions are mediated through a number of separate mechanisms. Successful treatment may involve identification of the relevant and most responsive mechanisms.

The field of brain neuroimaging continues to advance at a fast pace, and both old and new methods have been applied to the evaluation of FM. In an application of the older method of structural MRI, Kuchinad, et al. (75) have found that the size of specific brain regions is significantly reduced in patients with FM. A PET study of opioid receptors showed significant differences in endogenous opi- oid activity in FM (76), and the neuroimaging method of magnetic resonance spectroscopy (MRS) showed differences in the concentrations of metabolites related to neural activity in the insula (Harris, unpublished observations). Newer fMRI methods such as arterial spin labeling (ASL) have indentified insular mechanisms in patients that are related to increased activity at rest in the absence of painful stimulation and differences in the interconnections of the pain network at rest. A recent multi-center European trial has found that long term treatment with milnacipran results in changes in pain-evoked brain activity not observed with placebo treatment.

\section{CLINIMETRIC APPROACHES IN FIBROMYALGIA}

A range of treatments are employed to treat the various symptom facets of FM. Although some of these therapies have been tested in randomized controlled trials (RCT), there has been little standardization of an approach to trials or of the outcome measures used, and evaluating therapeutic effects on widely varying symptoms is difficult. To address the identification of core outcome domains, the Initiative on Methods, Measurement, and Pain Assessment in Clinical Trials (IMMPACT) (9) and Outcome Measures in Rheumatoid Arthritis Clinical Trials (OMERACT) (8) workshop convened a meeting to develop consensus recommendations for chronic pain clinical trials. The consensus of these groups has been that key outcomes should include pain, physical functioning, emotional functioning, patient global ratings of satisfaction, health-related quality of life, and adverse events $(8,9)$.

\section{Pain Assessment}

Chronic generalized pain is a core feature of FM $(77,78)$. A number of tools are available for the assessment of pain, including the visual analogue scale, the daily pain diary, and the McGill Pain Questionnaire (MPQ). Important issues that may influence assessment of pain in patients with FM include recall bias, use of paper versus electronic diaries to assess pain experiences, and pain scaling methods (79). The standard visual analogue scale is a $10 \mathrm{~cm}$ scale with a border on each end. The left end may be anchored by a numeric (i.e., "0") and/or verbal (e.g., "No pain at all") indicator. The right end may be anchored by a numeric (e.g., "10") 
and/or verbal (e.g., "Pain as bad as it could be") indicator. There are occasional distortions through photocopying and printing, but adjustments can be made so that the highest score is 10 . Huskisson et al. (80) also suggested that an alternative descriptive pain relief scale based on the indications "complete relief" "moderate relief," "slight relief" and "no pain relief" was possible, but this would be much less sensitive than the visual analogue scale. A number of studies have established that data from self-report visual analogue scales are reproducible. With the development of optical scanning technology for the automated computer entry of scores, visual analogue scales can be presented in a format of 11 small boxes or circles for patients to assess their pain from 0-10 (or 100) (81). Although formal direct comparative studies have not been performed to analyze the results of automated optical scanning, this scaling format appears to have criterion validity.

The visual analogue pain scale has proven to be a great advance in the assessment of pain. A daily diary has been used to assess the impact of pain in patients with FM and has been reported to be useful for demonstrating the manner in which pain influences activities of daily living in these individuals. The MPQ can provide detailed information on the characteristics of pain in FM (82). It includes 78 pain adjectives that are divided into 4 major categories (sensory, affective, evaluative, and miscellaneous sensory) $(82,83)$. This index takes 10 to 15 minutes to complete. Tender point assessment is a demonstrably useful part of the official ACR criteria for the diagnosis of FM. However, TPs are not unique to the syndrome. Tenderness is widespread in patients with FM rather than being confined to specific anatomic regions, and these individuals may also demonstrate more hypersensitivity to heat, cold, and electrical stimulation. Some methods of assessing tenderness (e.g., dolorimetry) may demonstrate increased pain sensitivity in patients with FM more objectively than palpation and are relatively independent of biasing factors or patient distress. In addition to tender point count, assessment of tender point intensity or score has been developed as an assessment tool. For example, the FM Intensity Score (FIS) is obtained by averaging the pain intensity scores (on a 0-10 scale) for the 18 sites assessed in the Manual Tender Point Survey (84).

\section{Psychological and behavioural assessment}

Psychological evaluation of the patient can provide useful information about the psychological and be- havioural features that may influence their pain and dysfunction and, conversely, provide a sense of the impact of pain, fatigue, and other symptoms on their psychological health $(85,86)$. It is often presumed that patients with greater psychological impairment and/or psychiatric pathology may be more symptomatic or resistant to improvement with therapeutic intervention. However, this assumption may be true only in some cases. Both in clinical practice and in drug trials, it is important to diagnose and effectively treat concomitant depression, anxiety, bipolar states, and especially, suicidal tendencies. In addition to a careful history, a number of screening tools are available for both clinical and research purposes, including the Multidimensional Pain Inventory, the Pain Behaviour Scale, the Dartmouth Pain Questionnaire, the Coping Strategies Questionnaire, the Ways of Coping Scale and the Illness Behaviour Questionnaire $(79,85)$.

\section{Fatigue assessment}

Fatigue is one of the core features of FM, and its measurement is important in both research and clinical settings. A variety of measures exist and have proven useful in measuring fatigue in other rheumatic diseases, such as RA and AS (87). These include the Multidimensional Fatigue Index, which measures various types of fatigue including physical and emotional (87); the Functional Assessment of Chronic Illness Therapy (FACIT) system, which has been validated in a number of disease states and may be customized to certain disease indications (88); And the Fatigue Severity Scale, which was originally developed for multiple sclerosis and lupus fatigue assessment (89). The advantage of such tools is their ability to explore the multiple dimensions of fatigue. More simple, single-question fatigue assessments are embedded within such composite instruments as the FM Impact Questionnaire (FIQ).

\section{Sleep assessment}

Multiple dimensions of sleep quality have been assessed in FM trials, including quantity, quality, ease of falling asleep, frequency of waking, and feeling refreshed upon awakening. Sleep quality can be assessed on a $100 \mathrm{~mm}$ linear scale with "sleep is no problem" at one extreme and "sleep is a major problem" at the other extreme. Similar scales can be used to rate number of awakenings, and "restedness" on awakening in the morning. The Medical Outcome Study (MOS) sleep scale is an example of an instrument used in an FM trial. 


\section{Quality of life and functional assessment}

Measurement of global sense of well being, quality of life, and functional capacity in multiple dimensions (physical, vocational, social, emotional) is a key area of assessment and is considered essential by regulatory agencies when contemplating approval of medications for chronic pain states $(90,91)$. Assessment with the MOS Short Form36 (SF-36) Health Survey (SF-36) has shown that patients with FM have reduced physical functioning, physical role functioning, body pain, general health, vitality, and social functioning compared to healthy subjects.

The SF-36 is a generic instrument with scores that are based on responses to individual questions, which are summarized in eight scales (bodily pain, physical functioning, general health perception, role function - physical aspect, role function - emotional aspect, vitality, social functioning, and mental health), each of which measures a health concept (92). These scales, weighed according to normative data, are scored from 0 to 100, with higher scores reflecting a better quality of life. The SF-36 has been validated for use in Italy, and it can be completed within 15 min by most people. The Nottingham Health Profile (NHP) is intended for primary health care to provide a brief indication of a patient's perceived emotional, social and physical health problems (93).

The questionnaire consisted of two parts, but only part I is now used: it contains 38 yes/no items that can be grouped into 6 domains (physical mobility, pain, sleep, social isolation, emotional reactions, and energy level) with each question weighted for severity. The sum of all weighted values in a given domain represents a continuum between 0 (best health) and 100 (worst health). The FM Impact Questionnaire (FIQ) is an assessment instrument designed to measure the components of health status that are believed to be most affected by FM patients. It is composed of 20 items and is used to measure FM patient status, progress and outcomes $(93,94)$. The FIQ is a brief, self-administered instrument that takes approximately 5 minutes to complete $(90,91)$.

\section{Response criteria}

It is not known whether improvement in pain intensity alone should define response to treatment in FM, given that the syndrome is characterized by multiple and varying symptoms. In an attempt to develop a multi-component criterion for response to treatment in FM patients, Simms, et al. (95) proposed that a meaningful response to treatment should be consid-
Table I - Proposed preliminary response criteria for fibromyalgia.

Improvement in at least 3 of the 4 measures; and at least 3 of the post-treatment scores must satisfy the respective cutoffs:

1. FIQ score $<5$ (range $0=$ no impact to $80=$ maximum impact)

2. Pain intensity rating $<5$ (11 point numeric rating scale; $0=$ no pain, $10=$ very severe pain)

3. Tender point count $<14\left(4 \mathrm{~kg} / \mathrm{cm}^{2}\right.$ pressure is applied with a dolorimeter and the patient rates pain from 0 [no pain] to 10 [worst pain ever experienced]; positive tender point defined as pain intensity at $>2$ )

4. Total tender point pain intensity score $<85$ (sum of pain intensity scores for the 18 ACR defined sites; range 0 to 180)

FIQ: Fibromyalgia Impact Questionnaire. ACR: American College of Rheumato-

ered to have been achieved if patients met 4 of the 6 following criteria: $50 \%$ reduction in pain, sleep, fatigue, patient global assessment, or physician global assessment; and an increase of $1 \mathrm{~kg}$ in mean total myalgic score. Application of these criteria in a trial that compared amitriptyline, cyclobenzaprine, and placebo in patients with FM indicated that about onethird of patients had at least short-term responses to active treatment. These authors attempted to improve the definition for a response to FM therapy by testing criteria using a known, effective treatment as a gold standard (96).

A set of preliminary criteria was developed using data from a placebo-controlled clinical trial of amitriptyline versus naproxen. The outcome measures with the highest sensitivity in discriminating between patients receiving amitriptyline versus placebo or naproxen were change in physician global assessment, change in tender point score, and patient sleep assessment.

This analysis resulted in the response criteria composed of physician global assessment, patient-assessed sleep score, and tender point score. More recently, Dunk,l et al. (97) proposed preliminary criteria for identifying responders in FM clinical trials that were based on a study of magnetic therapy in patients with this disease (Table I). These preliminary criteria identified responders with a sensitivity of $70.5 \%$ and specificity of $87.5 \%$; however, these criteria have not been validated in other clinical trials.

\section{CONCLUSIONS}

At present, there are no specific markers for FM; in fact, many of the existing factors are significant 
for study purposes only. The presence of these factors, however, helps researchers and clinicians to understand the pathogenetic mechanisms and to identify patient subgroups. Some of these factors could be used as indices of disease severity. The current literature is engaged in identifying and suggesting serological alterations or instrumental investigations as new, specific markers of FM; but it is necessary to identify precise biomarkers of disease in accordance with the criteria of feasibility and reproducibility for diagnostic and therapeutic purposes. Unfortunately, the symptoms of FM are not specific and there are no instrumental diagnostic tests for FM. Many differential diagnoses may be excluded via extensive clinical examination and patient history, and considering the overlap of FM with other medical conditions, treating physicians should be vigilant: chest-X-rays and abdominal ultrasonography are the first steps of general evaluation for all patients with suspected FM. Functional neuroimaging methods have revealed a large number of supraspinal effects in FM, a disorder mediated by mechanisms that are essentially unknown. The goal of future studies will be to assess whether these findings are associated with the mechanisms that initiate and maintain this disorder, or whether they represent supraspinal consequences of these unknown mechanisms. Evaluating therapeutic effects in FM is difficult because of the many facets of the syndrome. To address the identification of core outcome domains, the IMMPACT and OMERACT workshops are working to develop consensus recommendations for chronic pain clinical trials.

\begin{abstract}
SUMMARY
Fibromyalgia (FM) is a rheumatic disease characterized by musculoskeletal pain, chronic diffuse tension and/or stiffness in joints and muscles, easy fatigue, sleep and emotional disturbances, and pressure pain sensitivity in at least 11 of 18 tender points. At present, there are no instrumental tests or specific diagnostic markers for FM; in fact, many of the existing indicators are significant for research purposes only. Many differential diagnoses may be excluded by an extensive clinical examination and patient history. Considering overlap of FM with other medical conditions, the treating physicians should be vigilant: chest-X-rays and abdominal ultrasonography are the first steps of general evaluation for all the patients with suspected FM. Functional neuroimaging methods have revealed a large number of supraspinal effects in FM, a disorder mediated by mechanisms that are essentially unknown. Many treatments are used in FM patients, but evaluating their therapeutic effects in FM is difficult because the syndrome is so multifaceted. To address the identification of core outcome domains, the Initiative on IMMPACT and OMERACT workshop convened a meeting to develop consensus recommendations for chronic pain clinical trials.
\end{abstract}

Key words - Biomarkers, functional magnetic resonance, clinimetric approaches, polysomnography, tilting test. Parole chiave - Biomarkers, risonanza magnetica funzionale, clinimetria, polisonnografia, tilting test.

\section{REFERENCES}

1. Wolfe F, Smythe HA, Yunus MD. The American College of Rheumatology 1990 Criteria for the Classification of Fibromyalgia. Report of the Multicenter Criteria Committee. Arthritis Rheum 1990; 33: 160-72.

2. Magaldi M, Moltoni I, Biasi G, Marcolongo R. Modifications of calcium and magnesium ions in the intracellular fibromialgica pathophysiology of the syndrome. Minerva Med 2000; 91: 137-40.

3. Wolfe F, K Ross, Russell AJ, Herbert L. The prevalence and characteristics of fibromyalgia in the general population. Arthritis Rheum 1995; 38: 19-28.

4. Salaffi F, De Angelis R, Stancati A, Grassi W, Arche Pain M. Prevalence Investigation Group (MAPPING) study. Health-related quality of life in multiple musculoskeletal conditions: a cross-sectional population based epidemiological study. II. The MAPPING study. Clin Exp Rheumatol 2005; 23: 829-39.

5. Cook DB, Lange G, Ciccone DS, Liu WC, Steffener J, Natelson BH. Functional imaging of pain in patients with primary fibromyalgia. J Rheumatol. 2004, 31: 36478.

6. Gracely RH, Petzke F, Wolf JM, Clauw DJ. Functional magnetic resonance imaging evidence of augmented pain processing in fibromyalgia. Arthritis Rheum. 2002, 46: 1333-43.

7. Buskila D, Sarzi-Puttini P, Atzeni F, Stisi S, Carrabba M. La sindrome fibromialgica: recenti acquisizioni. Progres Reum 2005; 6 (suppl 1): 148-57.

8. Turk DC, Dworkin RH, Allen RR, Bellamy N, Brandenburg N, Carr DB, et al. Core outcome domains for chronic pain clinical trials: IMMPACT recommendations. Pain 2003; 106: 337-45. 
9. Mease PJ, Clauw DJ, LM. Arnold, Goldenberg DL, Witter J, Williams DA, et al. Fibromyalgia syndrome. OMERACT 7 Workshop. J Rheumatol 2005; 32: 2270-7.

10. Mease P. Fibromyalgia syndrome. review of clinical presentation, pathogenesis, outcome measures and treatment. J Rheumatol 2005; 32: 6-21.

11. Sarzi-Puttini P, Atzeni F. La sindrome fibromialgica. Riabilitazione reumatologica approccio multidisciplinare. Ed. S. Maddali Bongi. 2008; 979-94.

12. Wilson RB, Gluck OS, Tesser JR, Rice JC, Meyer A, Bridges AJ. Antipolymer antibody reactivity in a subset of patients with fibromyalgia correlates with severity. J Rheumatol 1999; $26: 402-7$.

13. Werle And Fischer HP, Muller A, Fiehn W, Eich W. Antibodies against serotonin have no diagnostic relevance in patients with fibromyalgia syndrome. J Rheumatol 2001; 28: 595-600.

14. Bazzichi L, Rossi A, Giuliano T, De Feo F, Giacomelli C, Consensi A, et al. Association between thyroid autoimmunity and fibromyalgic disease severity. Clin Rheumatol 2007; 9.

15. Werle And Jakel HP, Muller A, Fischer HP, Fiehn W. Eich Serum Hyaluronic acid levels are elevated in arthritis patients, but normal and not associated with clinical data in patients with fibromyalgia syndrome. Lab Clin 2005; 51: 11-19.

16. Wigley RD, B, EM Chambers. Hyaluronic acid serum levels in fibromyalgia, non-specific arm disorder, and controls. J Rheumatol 2001; 28: 2563.

17. Maes M, Verkerk R, Delmeire L, Van Gastel A, Van Hunsel F, Scharpe S. Serotonergic markers and lowered plasme branched-chain amino-acid concentrations in fibromyalgia. Psychiatry Res 2000; 97 : 11-20.

18. Sprott H, A Muller, H. Heine. Collagen cross-links in fibromyalgia syndrome. Z. Rheumatol 1998; 57 : 52-5.

19. Jaschko G, Hepp U, Berkhoff M, Schmet M, Michel BA, Gay S, Sprott H. Serum serotonin levels are not useful in diagnosing fibromyalgia. Ann Rheum Dis 2007; 66: 1267-8.

20. Offenbaecher M, Bondy B, De Jonge St, Glatzeder K, Krüger M, Schoeps P, et al. Possible association of fibromyalgia with a polymorphism in the serotonin transporter gene regulatory region. Arthritis Rheum 1999; 42: 2482-8.

21. Dorshkind K, Horseman ND. The roles of prolactin, growth hormone, insulin-like growth factor-1, and thyroid hormones in lymphocyte development and function: insights from genetic models of hormone and hormone receptor deficiency. Endocr Rev 2000; 21: 292-312.

22. Hocherel K, Farber L, S Ladenburger, Vosshage D, Stratz T, Muller W, Grobecker H. Effect of tropisetron on circulating catecholamines and other putative biochemical markers in serum of patients with fibromyalgia. Scand J Rheumatol 2000; 113: 46-8.

23. Bazzichi L, Rossi A, MassimettiG, Giannaccini G, Giuliano T, De Feo F, et al. Cytokine patterns in fibromyalgia and their correlation with clinical manifestations. Clin Exp Rheumatol 2007; 25: 225-30.

24. Bagis S, Tamer L, Sahin G, Bilgin R H Guler, Ercan
B, Erdogan C. Free radicals and antioxidants in primary fibromyalgia: an oxidative stress disorder? Rheumatol Int 2005; 25: 188-90.

25. Lund I Lundeberg T, Carleson J, H Sonnerfors, Uhrlin B Svensson E. Corticotropin releasing factor in the urine: a possible biochemical markers of fibromyalgia. Responses to massage and guided relaxation. Neurosci Lett 2006; 403: 166-71.

26. Baraniuk JN, Casado B, H Maibach, Clauw DJ, Pannell LK, Hess SS. A chronic fatigue syndrome-related proteome in human cerebrospinal fluid. BMC Neurol 2005; 5: 22.

27. McLean S, Williams DA, Stein PK, Harris RE, Lyden AK, Whalen G, et al. Cerebrospinal fluid corticotropinreleasing factor concentration is associated with pain but not fatigue symptoms in patients with fibromialgia. Neuropsychopharmacology 2006; 31: 2776-82.

28. Sarchielli P, Alberti A, Candeliere A, Floridi A, Capocchi G, Calabresi P. Glial cell line-derived neurotrophic factor and somatostatin levels in cerebrospinal fluid of patients affected by migraine and fibromialgia. Cephalalgia 2005; 26: 409-15.

29. Bazzichi L, Giannaccini G, Betti L, Mascia G, Fabbrini L, Italiani P, et al. Alteration of serotonin transporter density and activity in Fibromyalgia. Arthritis Res Ther 2006; 8: R99 (doi: 10.1186/ar1982).

30. Bazzichi L, Giannaccini G, Betti L, Italiani P, Fabbrini L, De Feo F, et al. Peripheral benzodiazepine receptors on platelets of fibromyalgia patients. Clin Biochem 2006, 39: 867-72.

31. Kaufmann I, Eisner C, Richter P, Huge V, Beyer A, Chouker A, et al. Lymphocyte subsets and the role of Th1/Th2 balance in stressed chronic pain patients. Neuroimmunomodulation 2008; 14: 272-80.

32. Kim SH, Kim DH, Oh DH, Clauw DJ. Characteristic electron microscopic findings in the skin of patients with fibromialgia-preliminary study. Clin Rheumatol. 2008; 27: 219-23.

33. Nampiaparampil DE, Shmerling RH. A review of fibromyalgia. Am J Manag Care 2004; 10: 794-800.

34. Clauw DJ, Crofford LJ. Chronic widespread pain and fibromyalgia: what we know and what we need know. Best Pract Res Clin Rheumatol 2003;17:685-701.

35. Daoud KF, Barkhuizen A. Rheumatic mimics and selected triggers of fibromyalgia. Curr Pain Headache Rep 2002; 6: 284-288.

36. Wolfe F, Cathey MA, Kleinheksel SM. Fibrositis (fibromyalgia) in rheumatoid arthritis. J Rheumatol 1984; 11: 814-8.

37. Middleton GD, McFarlin JE, Lipsky PE. The prevalence and clinical impact of fibromyalgia in systemic lupus erythematosus. Arthritis Rheum 1994; 37 : 1181-8.

38. Bonafede RP, Downey DC, Bennetr RM. An association of fibromyalgia with primary Sjogren's syndrome: a prospective study of 72 patients. J Rheumatol 1995; 22: 133-6.

39. Wolfe F, Cathey MA. Prevalence of primary and secondary fibrositis. J Rhematol 1983; 33: 160-72.

40. Esther H, Barkhuizen A. Update on Rheumatologic 
mimics of fibromyalgia. Curr Pain Head Rep 2006; 10: 327-332.

41. Klippel JH, Crofford LJ, Stone JH, Weyand CM, eds. Primer on the rheumatic diseases. Atlanta: Arthritis Foundation; 2001.

42. Ostergaard M., Ejbjerg B, Szkudlarek M. Imaging in early rheumatoid arthritis: roles of magnetic resonance imaging, ultrasonography, conventional radiography and computed tomography. Best Pract Res Clin Rheumatol 2005; 19: 91-116.

43. Joshua F, Lassere M, Bruyn GA, Szkudlarek M, Naredo E, Schmidt WA, et al. Summary findings of a systematic review of the ultrasound assessment of synovitis. J Rheumatol 2007; 34: 839-47.

44. Grassi W, Filippucci E. Ultrasonography and the rheumatologist. Curr Opin Rheumatol 2007; 19: 55-60.

45. Khan MA. Update on spondyloarthropathies. Ann Intern Med 2002; 136: 896-907.

46. Fitzcharles MA, Esdaile J. The overdiagnosis of fibromyalgia syndrome. Am J Med 1997; 103: 44-50.

47. Zochling J, Baraliakos X, Hermann KG, Braun J. Magnetic resonance imaging in ankylosing spondylitis. Curr Opin Rheumatol 2007; 19: 346-52.

48. Cervera R, Khamashta MA, Font J, Sebastiani GD, Gil A, Lavilla P, et al. Morbidity and mortality in systemic lupus erythematosus during a 10 -year period. Medicine 2003; 82: 299-308.

49. Fitzpatrick TB, Johnson RA, Wolff K, eds et al. Color Atlas and Synopsis of Clinical Dermatology. New York: The McGraw-Hill Companies; 1997.

50. Martinez-Lavin M. Overlap of Fibromyalgia with other medical conditions. Curr Pain Head Rep 2001; 5: 347-50.

51. Martinez-Lavin M, Hermosillo AG. Autonomic nervous system dysfunction may explain the multi-system features of fibromyalgia. Semin Arthritis Rheum 2000; 29: 197-9.

52. Salaffi F, Carotti M, Argalia G, Salera D, Giuseppetti GM, Grassi W. Usefulness of ultrasonography and color Doppler sonography in the diagnosis of major salivary gland diseases. Reumatismo 2006; 58: 138-56.

53. Al-Allaf AW, Mole PA, Paterson CR, Pullar T. Bone health in patients with fibromyalgia. Rheumatology 2003; 42: 1202-6.

54. Briani C, Doria A, Sarzi-Puttini P, Dalakas MC. Update on idiopatic inflammatory myopathies. Autoimmunity 2006; 39: 161-70.

55. Pamuk ON, Cakir N. The frequency of thyroid antibodies in fibromyalgia patients and their relationship with symptoms. Clin Rheumatol 2007; 26: 55-9.

56. Garrison RL, Breeding PC. A metabolic basis for fibromyalgia and its related disorders: the possible role of resistance to thyroid hormone. Med Hypotheses 2003; 61: 182-9.

57. Buskila D. Hepatitis C-associated arthritis. Curr Opin Rheumatol 2000; 12: 295-9.

58. Adak B, Tekeoglu I, Ediz L, Budancamanak M, Yazgan T, Karahocagil K, et al. Fibromyalgia frequency in hepatitis B carriers. J Clin Rheumatol 2005; 11: 157-9.

59. Reilly PA. The differential diagnosis of generalized pain. Baillieres Best Pract Res Clin Rheumatol 1999; 13: 391-401.

60. Dreyer L, Mellemkjaer L, Kendall S, Jensen B, Danneskiold-Samsøe B, Bliddal H. Increased cancer risk in patients referred to hospital with suspected fibromyalgia. J Rheumatol 2007; 34: 201-6.

61. Martinez-Lavin M. Biology and therapy of fibromyalgia. Stress, the stress response system, and fibromyalgia. Arthritis Res Ther 2007; 9: 216 (doi: 10.1186/ar 2146).

62. Furlan R, Colombo S, Perego F, Atzeni F, Diana A, Barbic F, et al. Abnormalities of cardiovascular neural control and reduced orthostatic tolerance in patients with primary fibromyalgia. J Rheumatol. 2005; 32: 1787-93.

63. Sarzi-Puttini P, Rizzi M, Andreoli A, Panni B, Pecis M, Colombo S, et al. Hypersomnolence in fibromyalgia syndrome. Clin Exp Rheumatol 2002; 20: 69-72.

64. Rizzi M, Sarzi-Puttini P, Atzeni F, Capsoni F, Andreoli A, Pecis M, et al. Cyclic alternating pattern: a new marker of sleep alteration in patients with fibromyalgia? J Rheumatol 2004; 31: 1193-9.

65. Mountz JM, Bradley LA, Modell JG, Alexander RW, Triana-Alexander M, Aaron LA, et al. Fibromyalgia in women. Abnormalities of regional cerebral blood flow in the thalamus and the caudate nucleus are associated with low pain threshold levels. Arthritis Rheum 1995; 38: 926-38.

66. Kwiatek R, Barnden L, Tedman R, Jarrett R, Chew J, Rowe C, Pile K. Regional cerebral blood flow in fibromyalgia: single-photon-emission computed tomography evidence of reduction in the pontine tegmentum and thalami. Arthritis Rheum. 2000; 43: 2823-33.

67. Cohen-Gadol AA, Bradley CC, Williamson A, Kim JH, Westerveld M, Duckrow RB, et al. Normal magnetic resonance imaging and medial temporal lobe epilepsy: the clinical syndrome of paradoxical temporal lobe epilepsy. J Neurosurg 2005; 103: 768-9.

68. Iadarola MJ, Max MB, Berman KF, Byas-Smith MG, Coghill RC, Gracely RH, Bennett G. Unilateral decrease in thalamic activity observed with positron emission tomography in patients with chronic neuropathic pain. Pain 1995; 63: 55-64.

69. Di Piero V, Jones AK, Iannotti F, Powell M, Perani D, Lenzi GL, Frackowiak RS. Chronic pain: A PET study of the central effects of percutaneous high cervical cordotomy. Pain 1991; 46: 9-12.

70. Petzke F, Clauw DJ, Ambrose K, Khine A, Gracely RH. Increased pain sensitivity in fibromyalgia: effects of stimulus type and mode of presentation. Pain 2003; 105: 403-13.

71. Grant MA, Farrell MJ, Kumar R, Clauw DJ, Gracely RH. fMRI evaluation of pain intensity coding in fibromyalgia patients and controls. Arthritis Rheum $2001 ; 44$.

72. Giesecke T, Gracely R H, Williams DA, Geisser M, Petzke F, Clauw DJ. The relationship between depression, clinical pain, and experimental pain in a chronic pain cohort. Arthritis Rheum 2005; 52: 1577-84.

73. Burton AK, Tillotson KM, Main CJ, Hollis S. Psy- 
chosocial predictors of outcome in acute and subchronic low back trouble. Spine 1995; 20: 722-8.

74. Gracely RH, Geisser ME, Giesecke T, Grant MA, Petzke F, Williams DA, Clauw DJ. Pain catastrophizing and neural responses to pain among persons with fibromyalgia. Brain 2004; 127: 835-43.

75. Kuchinad A Scweinhardt P Seminowicz DA Wood PB Chizh BA Bushnell MC. Accelerated brain gray matter loss in fibromyalgia patients: premature. J Neurosci 2007; 27: 4004-7.

76. Harris RE, Clauw DJ, Scott DJ, McLean SA, Gracely RH, Zubieta JK. Decreased central mu-opioid receptor availability in fibromyalgia. J Neurosci 2007; 2: 10000-6.

77. Mäntyselkä P, Kumpusalo E, Ahonen R, Kumpusalo A, Kauhanen J, Viinamäki H, et al. Pain as a reason to visit the doctor; a study in Finnish primary health care. Pain 2001; 89: 175-80.

78. Macfarlane GJ, Morris S, Hunt IM, Benjamin S, McBeth J, Papageorgiou AC, et al. Chronic widespresd pain in the community: the influence of psychological symptoms and mental disorder on healthcare seeking behavior. J Rheumatol 1999; 26: 413-9.

79. Salaffi F, Carotti M. Semeiotica e valutazione del dolore muscoloscheletrico. In "Clinimetria delle malattie muscoloscheletriche. Scale e punteggi” Ed Mattioli $1885 ; 19-58,2007$.

80. Scott-Huskisson EC. Graphic Representation of pain. Pain 1976; 2: 175-84.

81. Salaffi F, Stancati A, Silvestri CA, Ciapetti A, Grassi W. Minimal clinically important changes in chronic musculoskeletal pain intensity measured on a numerical rating scale. Eur J Pain 2004; 8: 283-91.

82. Melzack R. The McGill Pain questionnaire: major properties and scoring methods. Pain 1985; 1: 85-92.

83. Salaffi F, Nolli M, Cavalieri F, Ferraccioli GF. Confronto tra indici algometrici nella valutazione dell'esperienza algica in Reumatologia. Utilità della versione italiana del questionario algologico McGill. Reumatismo 1990; 42: 19-31.

84. Sinclair D, Starz T, Turk D. The manual Tender Point Survey. [Internet]. [Accessed July, 2005]. Available from National Fibromyalgia Association: http://fmawa re.org/doctor/tenderpt.htm

85. Fordyce WE, Lansky D, Calsyn DA, Shelton JL, Stolov
WC, Rock DL. Pain measurement and pain behavior. Pain 1984; 18: 53-69.

86. Scudds RA, Rollman GB, Harth M, McCain A. Pain perception and personality measures as discriminations in the classification of fibrositis. J Rheumatol 1987; 14: 563-9.

87. Belza BL, Henke CJ, Yelin EH, Epstein WV, Gillis CL. Correlates of fatigue in older adults with rheumatoid arthritis. Nurs Res 1993; 42: 93-9.

88. Webster K, Cella D, Yost K. The Functional Assessment of Chronic Illness Therapy (FACIT) Measurement System: properties, applications, and interpretation. Health Qual Life Outcomes 2003; 1: 79.

89. Krupp LB, LaRocca NG, Muir-Nash J, Steinberg AD. The Fatigue Severity Scale. Application to patients with multiple sclerosi and systemic lupus erythematosus. Arch Neurol 1989; 46: 1121-3.

90. Hays R, Stewart A. Measuring functioning and well-being. In: Stewart A, Ware J, editors. Durham, NC: Duke University Press; 1992: 232-59.

91. Franchignoni F, Salaffi F. Generic and specific measures for outcome assessment in orthopaedic and rheumatologic rehabilitation. In: Assessment in Physical Medicine and Rehabilitation - Advances in Rehabilitation. M. Barat, F. Franchignoni Eds. 2004; 16: 45-77.

92. Ware JE Jr, Sherbourne CD. The MOS 36-item short form health survey (SF-36). Conceptual frame-work and item selection. Med Care 1992; 30: 473-81.

93. Hunt SM, McEven J, McKenna SP. Measuring health status: a new tool for clinicians and epidemiologists. J Roy Coll Gen Pract 1985; 35: 185-8.

94. Burckhardt CS, Clark SR, Bennett RM. The Fibromyalgia Impact Questionnaire: development and validation. J Rheumatol 1991; 18: 728-33.

95. Sarzi-Puttini P, Atzeni F, Fiorini T, Panni B, Randisi $\mathrm{G}$, Turiel M, et al. Validation of an Italian version of the Fibromyalgia Impact Questionnaire (FIQ-Q). Clin Exp Rheumatol 2003; 21: 459-64.

96. Simms RW, Felson DT, Goldenberg DL. Development of preliminary criteria for response to treatment in fibromyalgia syndrome. J Rheumatol 1991; 18: 1558-63.

97. Dunkl PR, Taylor AG, McConnell GG, Alfano AP, Conaway MR. Responsiveness of fibromyalgia clinical trial outcome measures. J Rheumatol 2000; 27 : 2683-91. 